\title{
Improvement of putrescine production through the arginine decarboxylase pathway in Escherichia coli K-12
}

\author{
Kullathida Thongbhubate, Kanako Irie, Yumi Sakai, Akane Itoh and Hideyuki Suzuki (i)
}

\begin{abstract}
In the bio-based polymer industry, putrescine is in the spotlight for use as a material. We constructed strains of Escherichia coli to assess its putrescine production capabilities through the arginine decarboxylase pathway in batch fermentation. N-Acetylglutamate (ArgA) synthase is subjected to feedback inhibition by arginine. Therefore, the 19th amino acid residue, Tyr, of $\arg A$ was substituted with Cys to desensitize the feedback inhibition of arginine, resulting in improved putrescine production. The inefficient initiation codon GTG of argA was substituted with the effective ATG codon, but its replacement did not affect putrescine production. The essential genes for the putrescine production pathway, speA and speB, were cloned into the same plasmid with $\arg A^{A T G ~ Y 19 C}$ to form an operon. These genes were

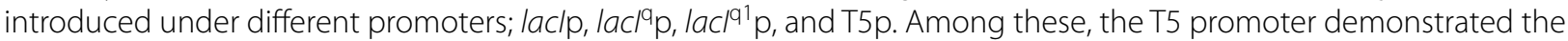
best putrescine production. In addition, disruption of the puuA gene encoding enzyme of the first step of putrescine degradation pathway increased the putrescine production. Of note, putrescine production was not affected by the disruption of patA, which encodes putrescine aminotransferase, the initial enzyme of another putrescine utilization pathway. We also report that the strain KT160, which has a genomic mutation of YifEE ${ }^{\mathrm{Q} 00 T A G}$, had the greatest putrescine production. At $48 \mathrm{~h}$ of batch fermentation, strain KT160 grown in terrific broth with $0.01 \mathrm{mM} \mathrm{IPTG}$ produced $19.8 \mathrm{mM}$ of putrescine.
\end{abstract}

Keywords: Glutamate-putrescine ligase, $N$-acetylglutamate synthase, Macrodomain Ori protein, Terrific broth

\section{Introduction}

Putrescine is a polyamine and consists of two amino groups and four methylene groups. This compound is widely distributed in living organisms (Pegg 1986; Michael 2016; Keller et al. 2019). Several studies have focused on putrescine as it regulates rapid cell proliferation and differentiation at the level of gene expression (Heby 1981; Michael 2018; Igarashi and Kashiwagi 2000, 2018, 2019). Yoshida et al. (2004) reported a correlation between putrescine and more than 600 genes related to the regulation of transcription. In addition, putrescine is used as a precursor of other polyamines, surfactants,

*Correspondence: hideyuki@kit.ac.jp

Division of Applied Biology, Kyoto Institute of Technology, Matsugasaki, Sakyo-Ku, Kyoto 606-8585, Japan and agrochemicals, and as a component of polymers such as nylon 4,6 (Schneider and Wendisch 2011; Wendisch et al. 2018; Hui et al. 2020). The polycondensation of putrescine and adipic acid is used to synthesize nylon 4,6 . Due to its flexibility and high solvent resistance properties, nylon 4,6 was introduced into the commercial field (Demco et al. 2007; Yamanobe et al. 2007). Polyamides are used in the electric vehicle industry as materials to develop a lighter body, interior, motor, controller, and electronic board of the car. Along with the expansion of the global electric vehicle market, the demand for putrescine is also increasing (Scott et al. 2007; Schneider and Wendisch 2010). There are two processes to synthesize putrescine, chemical and biological. However, the chemical process producing an intermediate, succinonitrile, releases dangerous and harmful compounds.
SpringerOpen
C The Author(s) 2021. Open Access This article is licensed under a Creative Commons Attribution 4.0 International License, which permits use, sharing, adaptation, distribution and reproduction in any medium or format, as long as you give appropriate credit to the original author(s) and the source, provide a link to the Creative Commons licence, and indicate if changes were made. The images or other third party material in this article are included in the article's Creative Commons licence, unless indicated otherwise in a credit line to the material. If material is not included in the article's Creative Commons licence and your intended use is not permitted by statutory regulation or exceeds the permitted use, you will need to obtain permission directly from the copyright holder. To view a copy of this licence, visit http://creativecommons.org/licenses/by/4.0/. 
On the other hand, the biological process is safe, environmentally friendly, and uses renewable feedstock (Sanders et al. 2007; Nguyen and Lee 2019; Li et al. 2020a).

Among the living organisms that can produce putrescine, bacteria are commonly used in research because they grow rapidly under simple culture conditions such as Escherichia coli. The knowledge of polyamines in E. coli was reviewed admirably by Tabor and Tabor (1985) a long time ago, but it is still valid today. E. coli has two putrescine synthetic pathways (Fig. 1): the ornithine decarboxylase (ODC) pathway and the arginine decarboxylase (ADC) pathway, which use ornithine and arginine as starting compounds, respectively (Fig. 1). Arginine is synthesized from glutamate via ornithine through a sequential reaction. The ODC pathway decarboxylates ornithine to putrescine by constitutive ornithine decarboxylase (SpeC) and/or inducible ornithine decarboxylase (SpeF) (Tabor and Tabor 1985). The other pathway, the ADC pathway, converts arginine to putrescine via agmatine. The conversion of arginine to agmatine is catalyzed by biosynthetic arginine decarboxylase (SpeA) and biodegradative arginine decarboxylase (AdiA). Subsequently, agmatine is hydrolyzed to putrescine by agmatinase (SpeB). Putrescine is catabolized by two pathways, the putrescine utilization pathway (Puu pathway) (Kurihara et al. 2005) and the putrescine aminotransferase (PatA)- $\gamma$-aminobutyraldehyde dehydrogenase (PatD) pathway. These catabolic pathways rely on glutamate-putrescine ligase (PuuA) and putrescine aminotransferase (PatA), respectively (Samsonova et al. 2003, 2005; Kurihara et al. 2008). S-Adenosylmethionine decarboxylase $(\mathrm{SpeD})$ generates decarboxylated $S$-adenosyl-L-methionine. Its $n$-propylamine is transferred to putrescine via spermidine synthase (SpeE) to synthesize spermidine (Tabor et al. 1986). Spermidine $N$-acetyltransferase (SpeG) converts spermidine to its inactive form, $\mathrm{N}$-acetylspermidine (Limsuwun and Jones, 2000). In addition, Haywood and Large (1985) reported that spe $G$ encodes a putative diamine acetyltransferase that converts putrescine to acetylputrescine in Candida boidinii. Although the use of putrescine by $E$. coli SpeG as a substrate has not been reported, the speG gene was knocked out in this study to prevent the possible loss of putrescine (Fig. 1). Because of the cationic function of polyamine, it cannot penetrate through the cell membrane. Two spermidine transporters, PotABCD and MdtJI, and six putrescine transporters, PuuP, YdcSTUV, PlaP, PotE, PotFGHI, and SapBCDF, have been identified (Kashiwagi et al. 1992; Pistocchi et al. 1993; Kurihara et al. 2009a, b; Kurihara et al. 2011; Saier et al. 2016; Sugiyama et al. 2016). We recently reported that PotFGHI can import spermidine under biofilm-forming conditions (Thongbhubate et al. 2021).
Qian et al. (2009) overproduced putrescine through the ODC pathway in E. coli K-12, and the batch culture experiment resulted in $1.68 \mathrm{~g} / \mathrm{L}(19.0 \mathrm{mM})$ in the $10 \mathrm{~g} / \mathrm{L}$ of the glucose-enriched medium. Recently, Li et al. (2020b) overexpressed the ADC pathway and improved putrescine production using E. coli BL21(DE3). They produced putrescine using an SOB medium supplemented with $8 \mathrm{~g} / \mathrm{L}$ of glucose and $12 \mathrm{~g} / \mathrm{L}$ of arginine, resulting in $4.77 \mathrm{~g} / \mathrm{L}$ of putrescine in batch culture. However, the latter method is a type of sequential enzymatic conversion of arginine to putrescine.

We found that the introduction of the plasmid that contains spe $A B$ produced more extracellular putrescine than that of the plasmids that contain speC or speABC. Therefore, we focused on fermentation of putrescine via the ADC pathway of E. coli K-12 without the addition of arginine. Here, genetic engineering was used as a tool to increase the production of putrescine. ArgA catalyzes the initial step of arginine biosynthesis (Rajagopal et al. 1998; Shin and Lee 2014; Ginesy et al. 2015). When arginine is overproduced, this compound affects $\mathrm{N}$-acetylglutamate synthase (ArgA) activity through negative feedback inhibition. Furthermore, the DNA-binding transcriptional dual regulator (ArgR) represses the transcription of the genes of $\arg$ regulons, including $\operatorname{argA}$. We not only attempted to enhance arginine synthesis, but also deleted genes related to the degradation or utilization of putrescine, in addition to transporters that uptake putrescine from the medium, such as potE, speG, patA, speD, argR and $p u u P A$, and altered the expression of genes related to the synthesis of putrescine, speA, speB, and other genes from plasmids (Fig. 1).

\section{Materials and methods}

\section{Construction of $E$. coli strains}

The E. coli strains used in this study are listed in Table 1. The chromosomal genes speD, and $\operatorname{argR}$ were replaced with FRT (FLP recombination target)-kan ${ }^{\mathrm{R}}$-FRT from the Keio gene knockout collection (Baba et al. 2006) by P1vir transduction (Miller 1972). The disruption of speG, potE, and the ATP binding site of the puuA gene were described previously (Kurihara et al. 2008, 2009b; Thongbhubate et al. 2021). The patA and potFGHI genes were disrupted by a method described previously (Datsenko and Wanner 2000) using pKD13 as a template for the PCR amplification with delta-ygjG F and delta-ygjG R as primers for patA, and potF-up and potI-down as primers for potFGHI (Additional file 1: Table S1). The $k a n^{\mathrm{R}}$ genes were eliminated from FRT- $k a n^{\mathrm{R}}$-FRT by Flp flippase carried by pCP20 (Datsenko and Wanner 2000). To confirm the deletion of genes, colony PCR was performed with primers (Additional file 1: Table S1) that annealed upstream and downstream of the genomic regions of 


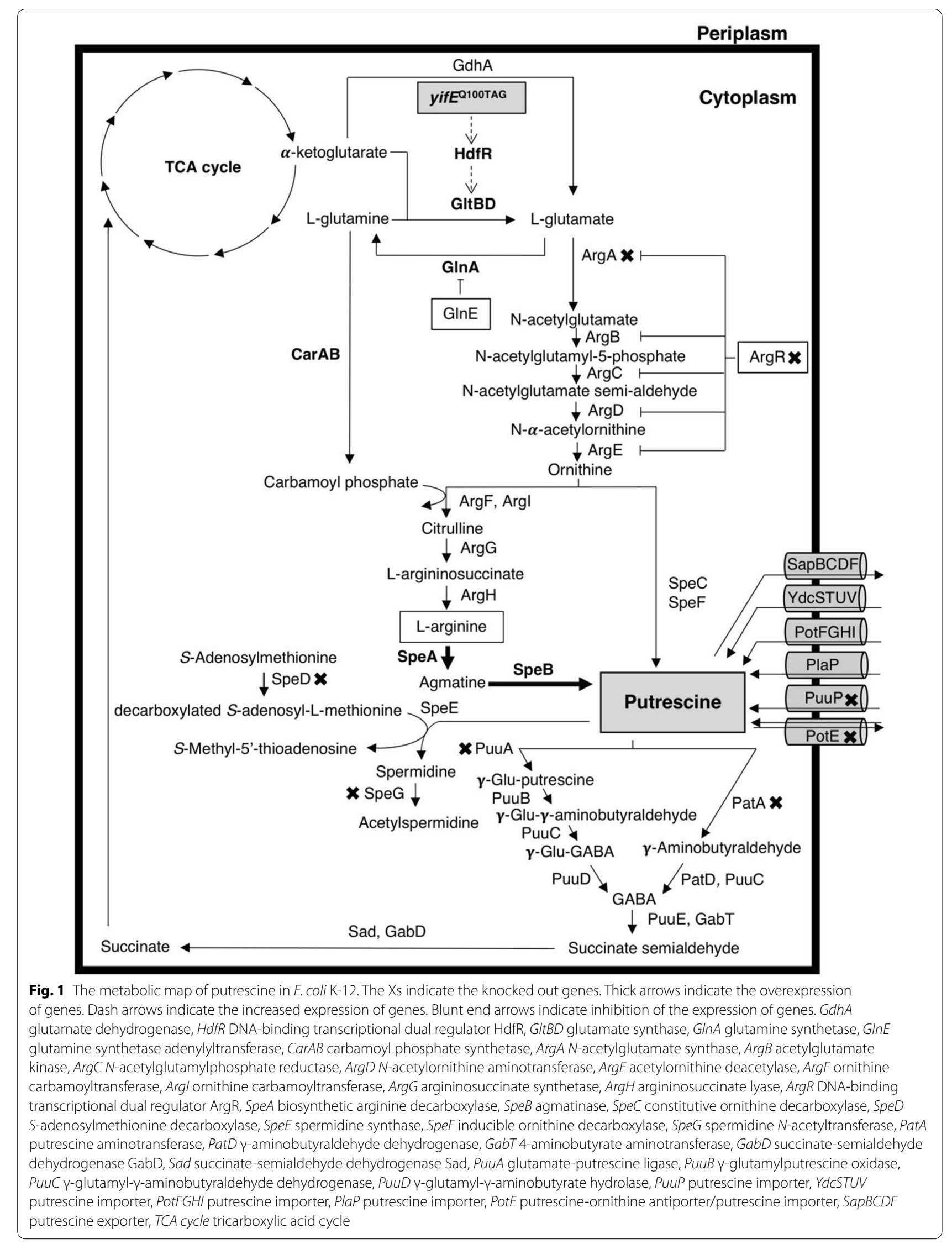


Table 1 Strains used in this study

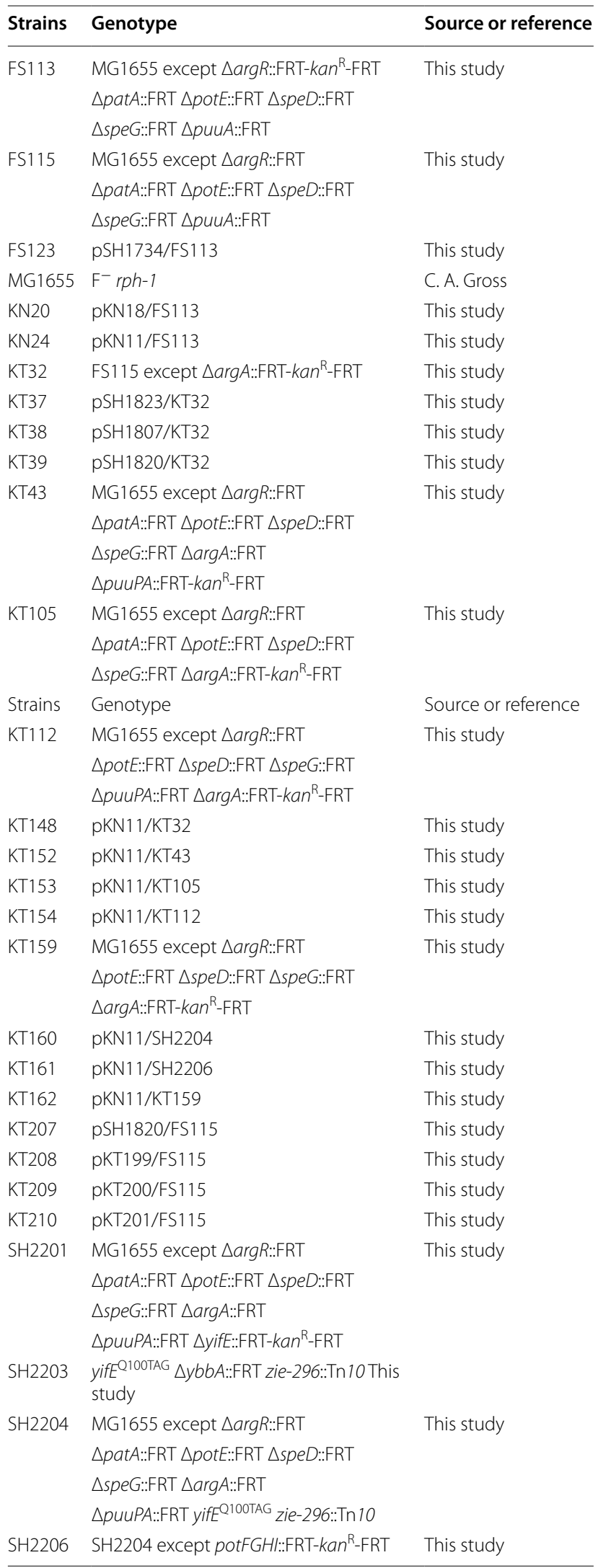

the target genes, and the sizes of the amplicons were measured. To construct SH2204, the yifE::FRT-kan ${ }^{\mathrm{R}}$ FRT of SH2201 was replaced with the yifE ${ }^{\mathrm{Q} 100 \mathrm{TAG}}$ using the zie-296::Tn10 as a co-transduction marker by P1vir phage grown on SH2203 to obtain SH2204, which was confirmed to be $\mathrm{Kan}^{\mathrm{S}}$. Then, the yifE region of SH2204 was amplified by PCR and the DNA sequence was confirmed. For DNA modification and strain construction, E. coli cells were grown in LB medium (Miller 1972). Where appropriate, culture media were supplemented with $30 \mu \mathrm{g} / \mathrm{mL}$ of kanamycin, $100 \mu \mathrm{g} / \mathrm{mL}$ of ampicillin, or $15 \mu \mathrm{g} / \mathrm{mL}$ of tetracycline. For the pre-cultures, $10 \mathrm{~mL}$ of LB medium was inoculated with a single colony in 100 $\mathrm{mL}$ Erlenmeyer flasks. Cultures were incubated at $37^{\circ} \mathrm{C}$ with reciprocal shaking at $120 \mathrm{rpm}$.

\section{Plasmid construction}

The plasmids used in this study are shown in Table 2 and the primers used to construct the plasmids are listed in Additional file 1: Table S2. The Wizard Plus SV Minipreps DNA Purification System (Promega; Madison, WI) was used to extract plasmid DNA from cells. PCR amplification was performed using KOD-plus DNA polymerase (Toyobo; Osaka, Japan). The QuikChange method (Stratagene; San Diego, CA) was used to generate $\arg A^{\mathrm{ATG} Y 19}$ of pSH1733 using KOD-plus DNA polymerase. There is a 137-base pair space between the speA and speB genes in the genome of MG1655. Therefore, the wild-type spe $A B$ genes may not be an operon. The spe $A$ and $s p e B$ genes on the plasmids used in this study are different from the wild-type genes on the genome. They are designed to have only a 21-base pair space with a Shine Dalgarno (SD) sequence between them, i.e., they were designed to be an operon. Consequently, the transcription of speA will also pass through speB. The $s p e C$ gene was amplified using genomic DNA of MG1655 as a template and primers with EcoRI and $S a c$ I recognition sites. After the amplified fragment was cleaved with these two enzymes, it was inserted between the EcoRI and SacI sites of $\mathrm{pQE}-80 \mathrm{~L}$ vector.

\section{Medium and culture conditions for putrescine production}

Pre-culture was carried out in $10 \mathrm{~mL}$ of LB medium in a 100-mL Erlenmeyer flask for $16 \mathrm{~h}$ at $37^{\circ} \mathrm{C}$ with a reciprocal shaking at $120 \mathrm{rpm}$. After $16 \mathrm{~h}$, the pre-culture was transferred to $10 \mathrm{~mL}$ of $\mathrm{LB}$ or terrific broth medium to adjust the initial density of the cells to an $\mathrm{OD}_{600}$ of 0.05 . The cultures were incubated at $37{ }^{\circ} \mathrm{C}$ with a reciprocal shaking at $120 \mathrm{rpm}$ until the turbidity $\mathrm{OD}_{600}$ reached 0.4. Then, IPTG was added to the main culture as needed. When ampicillin was required, $100 \mu \mathrm{g} / \mathrm{mL}$ of ampicillin was added to the media. 
Table 2 Plasmids used in this study

\begin{tabular}{|c|c|c|}
\hline Strains & Genotype & Source or reference \\
\hline pCP20 & $\begin{array}{l}\text { pSC101 replicon (Ts) bla } \text { cat }^{+} \\
\text {Flp(yRp) d857 }\end{array}$ & Datsenko and Wanner 2000 \\
\hline pFS29 & $\begin{array}{l}\text { pQE-80L except T5p lacO_lacO_ } \\
\text { spec }^{+}\end{array}$ & This study \\
\hline pKD13 & oriRy bla ${ }^{+}$FRT-kan ${ }^{\text {- }}$ FRT & Datsenko and Wanner 2000 \\
\hline pKN11 & $\begin{array}{l}\text { pQE-80L except T5p lacO_lacO } \\
\text { _speA_speB_argA }{ }^{\text {ATG } 19 C}\end{array}$ & This study \\
\hline pKN18 & $\begin{array}{l}\text { pQE-80L except T5p lacO_lacO } \\
\text { _speA_speB_argA }{ }^{\mathrm{ATG} Y 19 \mathrm{C}} \mathrm{T} 5 \mathrm{p} \\
\text { lacO_ } \\
\text { lacO_speC }\end{array}$ & This study \\
\hline pKT199 & $\begin{array}{l}\text { pQE-80L except } \\
\text { lac/919_lacO_speA_speB_argA }{ }^{9 T G} \\
\text { Y19C } \\
\text { lacl }\end{array}$ & This study \\
\hline pKT200 & $\begin{array}{l}\text { pQE-80L except } \\
\text { lac/191 P_lacO_speA_speB_argA }{ }^{\text {ATG }} \\
\text { lacl }\end{array}$ & This study \\
\hline pKT201 & $\begin{array}{l}\text { pQE-80L except } \\
\text { lacl919_lacO_speA_speB_argA }{ }^{9 T G} \\
\text { lacl }\end{array}$ & This study \\
\hline pQE-80L & $\begin{array}{l}\text { ColE1 replicon bla } l^{+} \operatorname{lacl}^{9} \mathrm{~T} 5 \mathrm{p} \\
\text { lacO_lacO-(His)6}\end{array}$ & Qiagen \\
\hline pSH1733 & pQE-80L except $\arg A^{\text {ATG Y19C }}$ & This study \\
\hline pSH1734 & $\begin{array}{l}\text { pQE-80L except T5p lacO_lacO_ } \\
\text { speC }^{+} \\
\text {_ } \operatorname{argA}^{\text {ATG Y19C }}\end{array}$ & This study \\
\hline pSH1807 & $\begin{array}{l}\text { pQE-80L except } \\
\operatorname{lac}_{\text {Y } 19 \mathrm{C} p \text { p_lacO_speA_speB_argA }}{ }^{\mathrm{ATG}} \\
\text { lacl }\end{array}$ & This study \\
\hline pSH1820 & $\begin{array}{l}\text { pQE-80L except } \\
\operatorname{lac}_{\text {Y19C }}{ }^{91} \text { P_lacO_speA_speB_argA }{ }^{A T G} \\
\text { lacl }\end{array}$ & This study \\
\hline pSH1823 & $\begin{array}{l}\text { pQE-80L except } \\
\text { laclp_lacO_speA_speB_argA ATG } \\
\text { Y19C } \\
\text { lacl }\end{array}$ & This study \\
\hline
\end{tabular}

\section{Sample preparation}

The culture was collected at the indicated time and used to measure the turbidity at $\mathrm{OD}_{600}$. The collected cultured was centrifuged at $18,000 \times \mathrm{g}$ at $4{ }^{\circ} \mathrm{C}$ for $5 \mathrm{~min}$. The supernatants were collected, and $25 \mu \mathrm{L}$ of $100 \%$ $(\mathrm{w} / \mathrm{v})$ trichloroacetic acid was mixed with $250 \mu \mathrm{L}$ of the three supernatants. Samples were filtrated through a Millex-LH Syringe Driven Filter Unit (Millipore; Billerica, MA).

\section{Measurement of putrescine concentrations}

The concentration of putrescine was measured using an LC-20 HPLC device (Shimadzu; Kyoto, Japan) equipped with a TSKgel Polyaminepak (Tosoh; Tokyo, Japan), as described previously (Kurihara et al. 2008). The temperature of the column was set at $50{ }^{\circ} \mathrm{C}$ and only one mobile phase solution was used. The flow rate of the mobile phase solution was $0.5 \mathrm{~mL} / \mathrm{min}$ and that of the detection reagent was $0.42 \mathrm{~mL} / \mathrm{min}$. The peak of putrescine was detected at 6 min under this analytical condition. Putrescine was purchased from Nacalai Tesque (Kyoto, Japan). The amounts of polyamines are presented as the average of three independent cultures with standard deviations.

\section{Data analysis}

All data were analyzed using SPSS Statistics 25 (IBM; Armonk, NY). The one-way analysis of variance (ANOVA) was used to determine significant differences.

\section{Results \\ Effects of the initiation codon and $\mathrm{Y} 19 \mathrm{C}$ substitution of ArgA}

The wild-type strain, MG1655 excretes only $0.18 \mathrm{mM}$ of putrescine in LB medium (data not shown). As arginine is a key substrate of putrescine synthesis through the ADC pathway, to increase putrescine production, we constructed plasmids with the ArgA desensitized to the feedback inhibition by arginine. In addition, the initiation codon of native ArgA is GTG, which is inefficient in translation initiation. Therefore, we generated a plasmid containing the $\operatorname{argA}$ gene with the effective ATG codon. Moreover, speA and $s p e B$ genes were introduced under the $l_{a c I} I^{\mathrm{q} 1}$ promoter along with the $\arg A$ gene in order to improve putrescine production. To compare the effects of both amino acid and initiation codon substitution, pSH1820 ( $\left.\arg A^{\mathrm{ATG}} \mathrm{Y19C}\right), \mathrm{pKT} 199\left(\arg A^{\mathrm{GTG}}\right.$ $\left.{ }^{\mathrm{Y} 19 \mathrm{C}}\right), \mathrm{pKT} 200\left(\arg A^{\mathrm{ATG} Y 19}\right)$, and pKT201 $\left(\arg A^{\text {GTG Y19 }}\right)$ were constructed, and strain FS115 was transformed to obtain KT207, KT208, KT209, and KT210, respectively. The strains were grown in LB medium with ampicillin and incubated at $37{ }^{\circ} \mathrm{C}$. The result is illustrated in Fig. 2 . KT207 excreted the highest concentration of putrescine into the medium, whereas strain KT210 excreted the lowest amount of putrescine. To compare the effects of the initiation codon, the strains were separated into two groups: GTG codon (KT208 and KT210) and ATG codon (KT207 and KT209). ATG codon exhibited a higher concentration of putrescine than the original initiation codon, GTG. In addition, Y19C substitution in strains KT207 and KT208 resulted in notably higher putrescine 


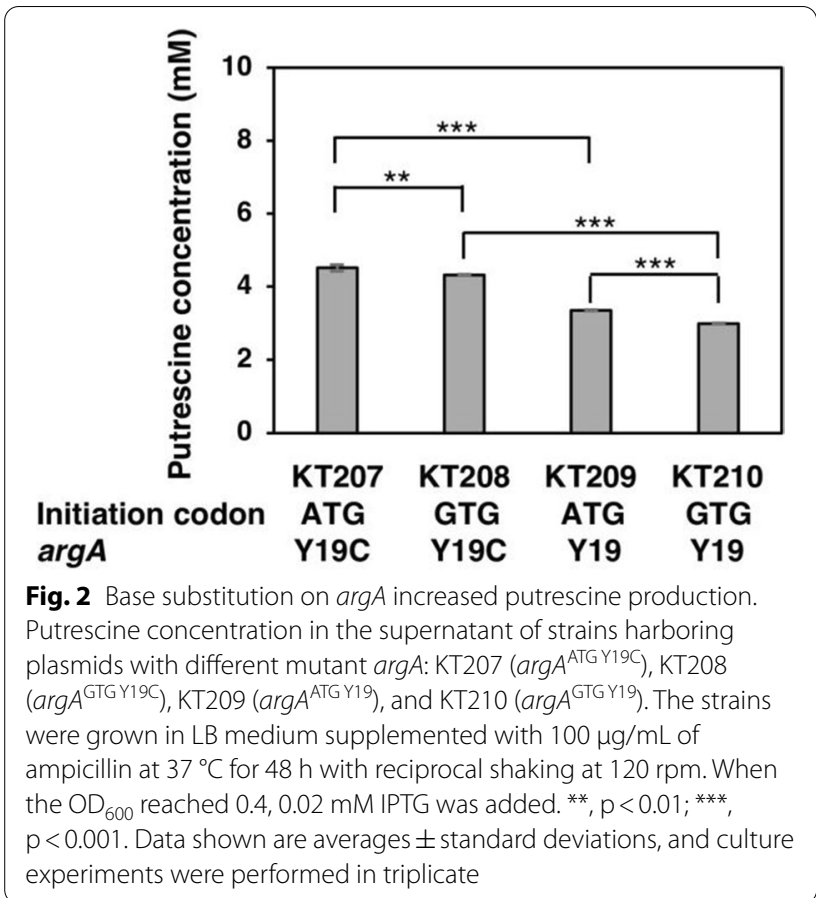

production than strains containing the native amino acid residue Y19 (KT209 and KT210).

\section{Effect of SpeA, SpeB, and SpeC on putrescine production}

There are ADC and ODC pathways for putrescine synthesis in E. coli. Whether the over-expression of ADC pathway only or of both ADC and ODC pathways is appropriate for the over-production of putrescine was not sure. To address this issue, we constructed a plasmid that has $\arg A^{\mathrm{ATG}} \mathrm{Y} 19 \mathrm{C}$ together with only speC gene under $\mathrm{T} 5$ promoter ( $\mathrm{pFS} 29)$ and compare with another two plasmids which have $\arg A^{\mathrm{ATG} Y 19 \mathrm{C}}$ with only spe $A B$ genes (pKN11) and $\arg A^{\mathrm{ATG}} \mathrm{Y} 19 \mathrm{C}$ with speAB and speC genes (pKN18). The plasmids were transformed into MG1655 as a host strain, resulting in FS123, KN24, and KN20, respectively. As depicted in Fig. 3A, the cell growth profiles of the above three strains were not different. However, the putrescine production of KN24, which has only spe $A B$ genes on a plasmid with $\arg A^{\text {ATG Y19C }}$ under T5 promoter, exhibited the highest putrescine content among these three strains (Fig. 3B). Therefore, the plasmid $\mathrm{pKN} 11$, which contains only speAB genes with $\arg A^{\mathrm{ATG} \text { Y19C }}$, was selected to use in further experiments.

\section{Effects of wild-type ArgA on ArgA ATG Y19C}

ArgA forms a homohexamer to be an active enzyme. When genomic $\arg A$ is wild-type, it may form a mixed hexamer of $\operatorname{Arg}^{\mathrm{wt}}$ and $\operatorname{Arg} \mathrm{A}^{\mathrm{Y} 19 \mathrm{C}}$. $\operatorname{Arg} \mathrm{A}^{\mathrm{wt}}$ may

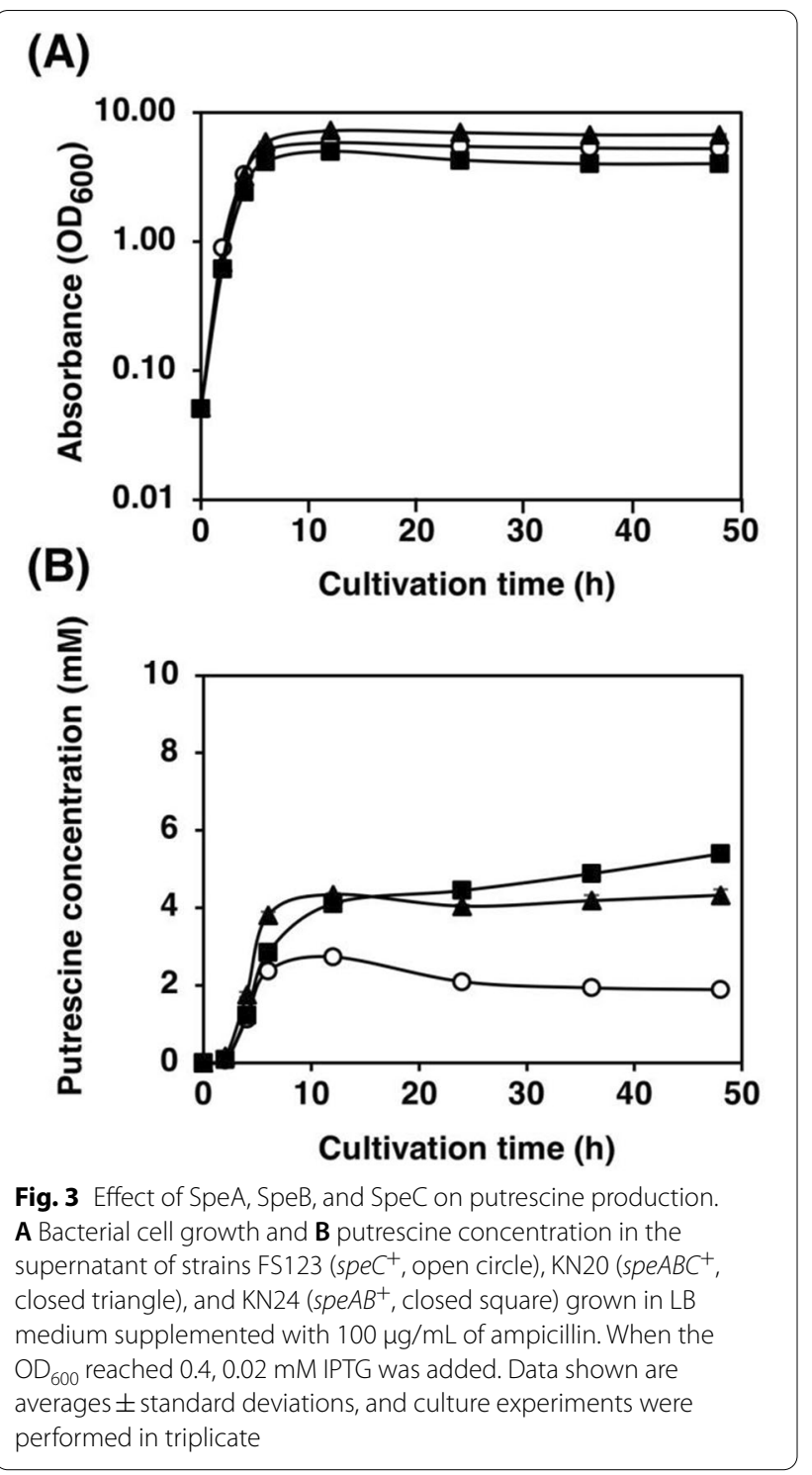

be dominant to $\operatorname{ArgA}^{\mathrm{Y} 19 \mathrm{C}}$ in the desensitization of arginine. To compare the effects of wild-type ArgA, the strains with and without $\operatorname{argA}, \mathrm{FS} 115\left(\arg A^{+}\right)$ and KT32 ( $\triangle \arg A)$, respectively, were constructed. The plasmid carrying speAB and $\arg A$ ( $\arg A^{\mathrm{ATG}}{ }^{\mathrm{Y} 19 \mathrm{C}}$ ) encoding desensitized ArgA ${ }^{\text {ATG Y19C }}$ under the regulation of the $l a c I^{q 1}$ promoter and lac operator was constructed (pSH1820) and used to transform the above-mentioned strains (FS115 and KT32), resulting in KT207 and KT39, respectively. To evaluate the effects of the coexistence of wild-type ArgA and desensitized ArgA ${ }^{\text {ATG Y19C }}$, KT207 and KT39 were used. As depicted in Fig. 4, the growth profile and putrescine production did not significantly differ between KT207 and KT39. 


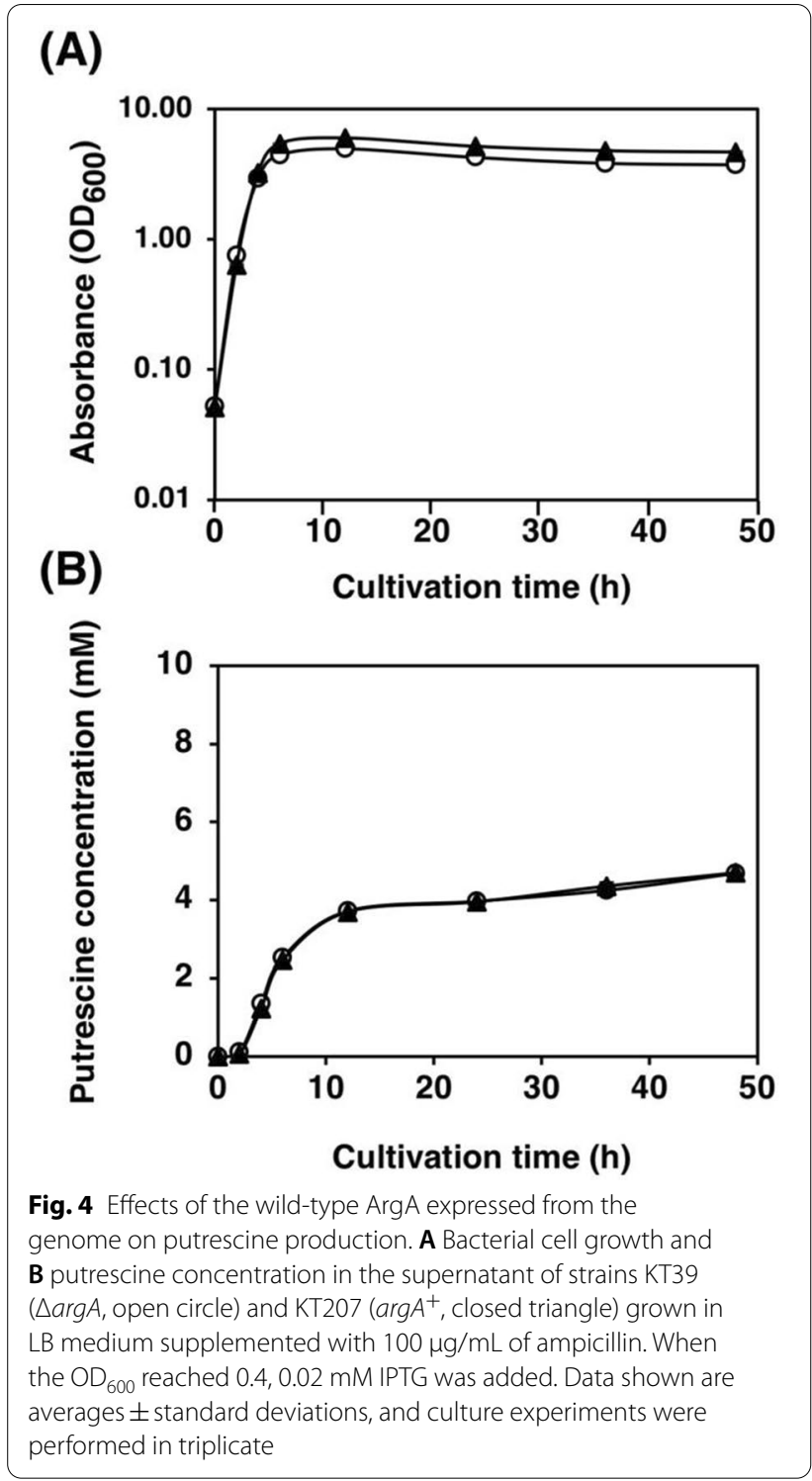

Effects of promoter strength on putrescine production

To promote the sequential reactions from arginine to putrescine, the promoter for speAB_argA ATG Y19C was evaluated. The concentrations of IPTG for inducible $l a c I$, $l a c I^{\mathrm{q}}$, $l a c I^{\mathrm{q} 1}$, and $\mathrm{T} 5$ promoters were compared. The lacI promoter of pSH1823 was replaced by $l_{a c I^{\mathrm{q}}}$ and $l_{a c I^{\mathrm{q}} 1}$ promoters, resulting in $\mathrm{pSH} 1807$ and pSH1820, respectively. The plasmid (pKN11) carrying the speAB_argA $A^{\mathrm{ATG} \mathrm{Y} 19 \mathrm{C}}$ under the T5 promoter and two lac operators was constructed. Strain KT32 was transformed with each plasmid to obtain KT37 (lacIp), KT38 (lac $\left.{ }^{\mathrm{q}} \mathrm{p}\right), \mathrm{KT} 39\left(\right.$ lac $\left.^{\mathrm{q} 1} \mathrm{p}\right)$, and KT148 (T5p). These strains were grown in LB medium with the addition of $0.02 \mathrm{mM}$ IPTG. The putrescine production of KT38 $\left(\right.$ lacI $\left.^{\mathrm{q}} \mathrm{p}\right)$ was not different from that of KT37 (lacIp).

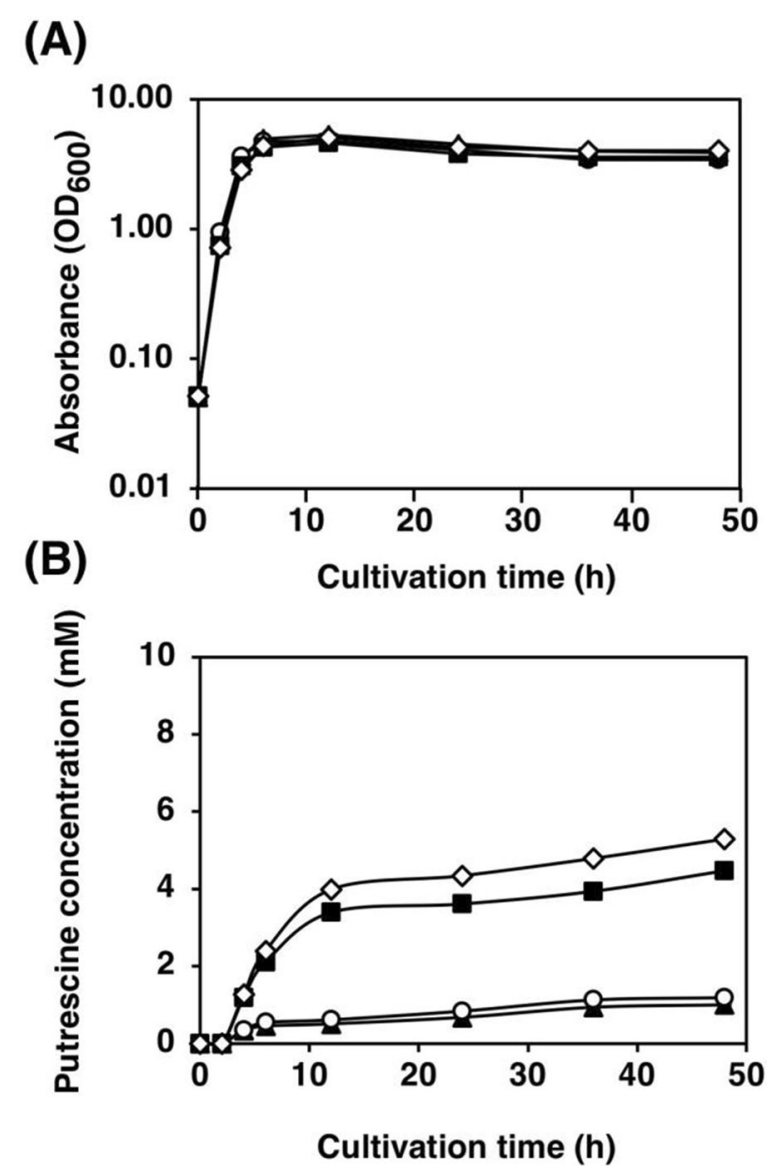

Fig. 5 Effects of promoters of speAB and desensitized $\arg A$ on putrescine production. A Bacterial cell growth and $\mathbf{B}$ putrescine concentration in the supernatant of strains KT37 (lacl promoter, closed triangle), KT38 (lacl ${ }^{9}$ promoter, open circle), KT39 (lac $\left.\right|^{91}$ promoter, closed square), and KT148 (T5 promoter, open diamond) grown in LB medium supplemented with $100 \mu \mathrm{g} / \mathrm{mL}$ of ampicillin. When the $\mathrm{OD}_{600}$ reached $0.4,0.02$ mM IPTG was added. Data shown are averages \pm standard deviations, and culture experiments were performed in triplicate

On the other hand, strains KT39 $\left(\right.$ lacI $\left.^{\mathrm{q} 1} \mathrm{p}\right)$, and KT148 (T5p) produced $349 \%$ and $431 \%$ more putrescine than strain KT37 (lacIp), respectively (Fig. 5B). Based on these results, KT148, carrying speAB and desensitized $\arg A$ under the T5 promoter and two lac operators, was used for further study. To optimize the IPTG concentration, it was varied from 0 to $0.20 \mathrm{mM}$. Among these concentrations, $0.03 \mathrm{mM}$ IPTG resulted in the highest putrescine production by KT148 in LB medium (data not shown).

\section{Disruption of genomic puuPA increases putrescine production}

To improve the accumulation of extracellular putrescine, the importer and degradation enzymes of putrescine 
should be eliminated. The host strains KT32 ( $\triangle p u u A$ $\triangle$ patA), KT43 ( $\triangle$ patA), KT112 ( $\triangle$ puuAP pat $\left.A^{+}\right)$, and KT159 (puuP $P^{+} A^{+}$ $p a t A^{+}$) were constructed to assess the effects of patA, рuиA, and puuP on putrescine production. The above strains were transformed by the plasmid pKN11 (T5p_speAB_argA $A^{\mathrm{ATG} \mathrm{Y} 19 \mathrm{C}}$ ), leading to strains KT148, KT152, KT153, KT154, and KT162. Among all strains, puuP $^{+} A^{+}$strains (KT153 and KT162) produced a lower amount of putrescine than the $\triangle p u u A$ (KT148) and $\triangle$ puuAP (KT152 and KT154) strains (Fig. 6B). However, there were no significant differences in the concentration of extracellular putrescine between KT153 ( $\Delta$ patA) and KT162 $\left(\right.$ pat $\left.^{+}\right)$strains.

\section{Effects of the medium on putrescine production}

The amount of putrescine production was compared using LB medium and terrific broth to optimize the medium for putrescine production. Strain KT152 grew and produced putrescine more in terrific broth than in LB (Fig. 7). At $48 \mathrm{~h}$ of incubation, strain KT152 excreted $10.9 \mathrm{mM}$ of extracellular putrescine in terrific broth, which was about twice as much as that in LB (Fig. 7B). Moreover, the IPTG concentration was optimized for cultivation in terrific broth. The concentration of IPTG was varied from 0 to $0.20 \mathrm{mM}$. The optimal concentration of IPTG for KT152 cultured in terrific broth was $0.02 \mathrm{mM}$ (data not shown).

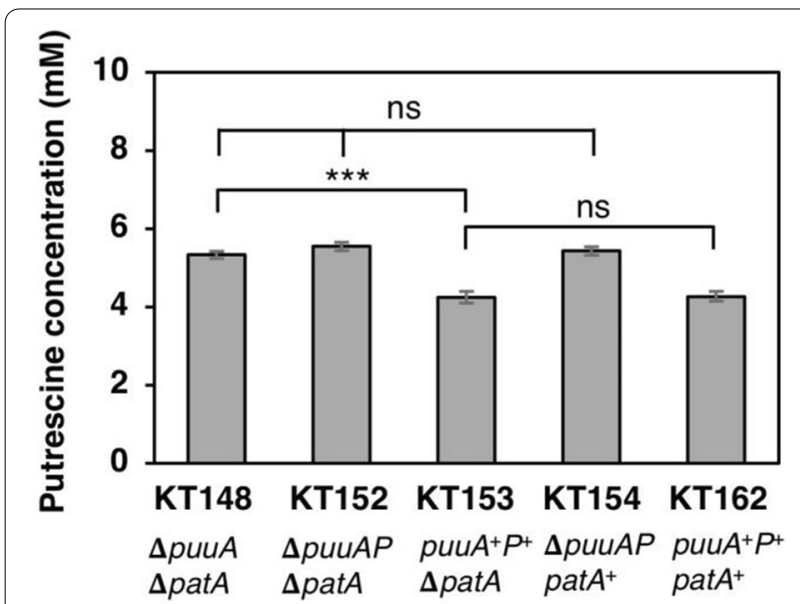

Fig. 6 Effects of patA, puuA, and puuP genes on the putrescine production. The amount of putrescine in the culture supernatant of the strains KT148, KT152, KT153, KT154, and KT162 grown in LB medium supplemented with $100 \mathrm{\mu g} / \mathrm{mL}$ of ampicillin for $48 \mathrm{~h}$. When the $\mathrm{OD}_{600}$ reached $0.4,0.03$ mM IPTG was added. ${ }^{* *}$, $\mathrm{p}<0.001$; ns, not significantly different. Data shown are averages \pm standard deviations, and culture experiments were performed in triplicate

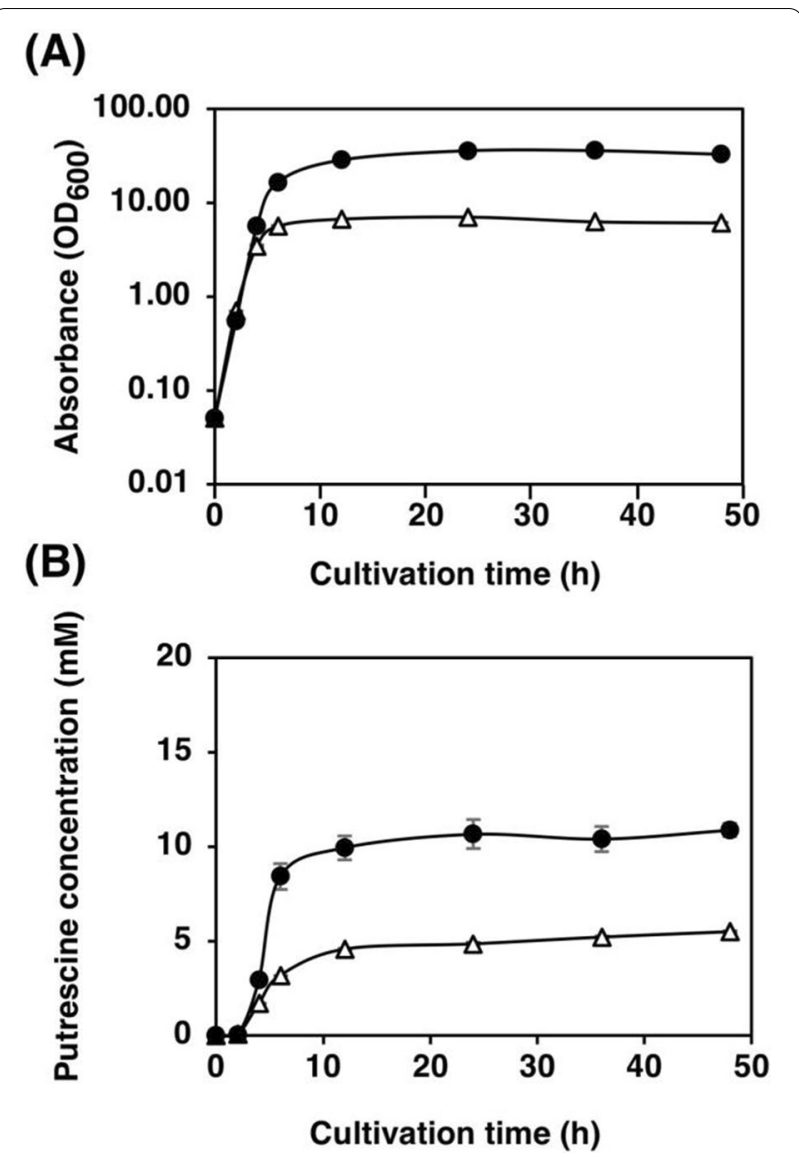

Fig. 7 Effects of culture media on putrescine production by strain KT152. A Bacterial cell growth and $\mathbf{B}$ putrescine concentration in the supernatant of the strain KT152, whose putrescine utilization pathway ( $\triangle$ puuAP $\triangle p a t A$ ) was disrupted. Open triangles represent the strain KT152 grown in the LB medium supplemented with $100 \mu \mathrm{g} / \mathrm{mL}$ of ampicillin; closed circles represent the strain KT152 grown in terrific broth supplemented with $100 \mu \mathrm{g} / \mathrm{mL}$ of ampicillin. When the $\mathrm{OD}_{600}$ reached $0.4,0.03$ mM IPTG was added. Data shown are averages \pm standard deviations, and culture experiments were performed in triplicate

\section{Effects of putrescine transporter PotFGHI and mutant YifE ${ }^{\text {Q100TAG }}$}

To clarify whether the disruption of the PotFGHI transporter and the mutation on YifE improved putrescine production, strain SH2204 was transformed with yifE::FRT- $k a n^{\mathrm{R}}$-FRT of SH2201 and the $y i f E^{\mathrm{Q} 100 \mathrm{TAG}}$ was replaced using zie-296:: $\operatorname{Tn} 10$ as a co-transduction marker by $\mathrm{P} 1$ vir phage grown on $\mathrm{SH} 2203$. The potFGHI operon of the strain SH2204 (yifE ${ }^{\mathrm{Q} 100 \mathrm{TAG}}$ ) was disrupted by P1vir transduction to obtain strain $\mathrm{SH} 2206$ (yifE ${ }^{\mathrm{Q} 100 \mathrm{TAG}}$ $\triangle p o t F G H I$ ). Strains KT43, SH2204, and SH2206 were transformed with pKN11 (T5p_speAB_argA ${ }^{\mathrm{ATG}}$ Y19C ), and strains KT152, KT160, and KT161 were obtained. Putrescine production by these strains in a terrific broth with 


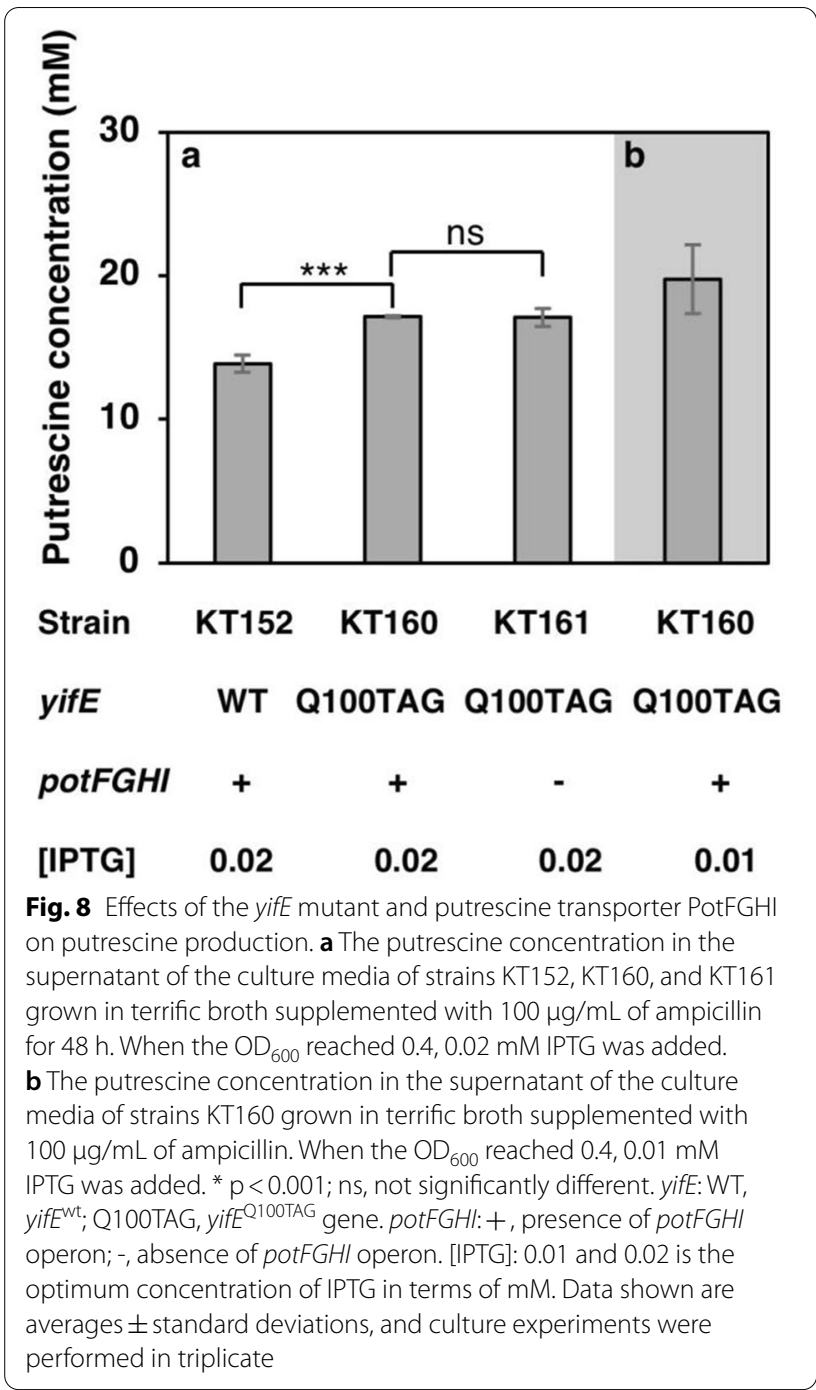

the addition of $0.02 \mathrm{mM}$ IPTG is compared in Fig. 8a. Samples were taken at $0,2,4,6,12,24,36$, and $48 \mathrm{~h}$ of incubation. Among these sampling times, the highest concentration of putrescine was observed at $48 \mathrm{~h}$ (data not shown). There was no significant difference in putrescine production between strains KT160 and KT161. However, the amount of extracellular putrescine excreted from both KT160 (yifE ${ }^{\mathrm{Q} 100 \mathrm{TAG}}$ potFGHI ${ }^{+}$) and KT161 (yifE ${ }^{\text {Q100TAG }} \Delta$ potFGHI) was 23\% higher than that by KT152 (yifE ${ }^{+}$potFGHI $I^{+}$(Fig. 8a). In addition, the IPTG concentration was optimized from 0 to $0.2 \mathrm{mM}$ for the cultivation of KT160 in terrific broth. The optimal concentration of IPTG for KT160 cultured in terrific broth was $0.01 \mathrm{mM}$ and the strain produced $19.8 \mathrm{mM}$ of putrescine (Fig. 8b).

\section{Discussion}

Efficient initiation codon of argA ${ }^{Y 19 C}$ improved the putrescine production- Arginine is a key substrate of putrescine synthesis through the ADC pathway. The biosynthetic pathway of arginine initiates with glutamate to $\mathrm{N}$-acetylglutamate by $\mathrm{N}$-acetylglutamate synthase (ArgA), which is encoded by $\arg A$. However, not only is the transcription of the $\arg A$ gene repressed by ArgR, but the activity of ArgA is also inhibited by the final product arginine ( $\mathrm{Lu}$ 2006; Sun et al. 2015; Xu and Zhang 2019a, b). To produce putrescine from glutamate, the repression of $\arg A$ by ArgR and the feedback inhibition of ArgA by arginine are of concern. Previously, Rajagopal et al. (1998) constructed plasmids with a point mutation in the $\operatorname{argA}$ gene. Among all point mutations, the strain with the Y19C mutation, which is an amino acid substitution of tyrosine with cysteine at the 19th codon, was able to produce the highest amount of arginine. According to the review of Igarashi and Kashiwagi (2010), the addition of putrescine stimulates the translation of polyamine modulons. As ArgA is a polyamine modulon (Igarashi et al. 2015), its translation can be stimulated by the increase in putrescine. The effects of the substitution of the GTG codon with the ATG codon was evaluated, but the substitution of GTG with ATG was not so effective as expected (Fig. 2). This may be because the plasmid we constructed has only 8 base pairs between the SD sequence and the ATG initiation codon, and it lacks the characteristics of a polyamine modulon. However, desensitization of ArgA by amino acid substitution at 19 positions from tyrosine to cysteine from the plasmid increased putrescine production (Fig. 2). And the strain with $\arg A^{\text {ATG Y19C }}$ had the highest amount of putrescine.

The effects of wild-type ArgA on desensitized ArgA- To confirm whether Arg ${ }^{\text {wt }}$ or $\operatorname{Arg} \mathrm{A}^{\text {ATG Y19C }}$ is dominant, we compared the putrescine production of KT39 (argA ${ }^{\mathrm{ATG}}$ $\left.\mathrm{Y} 19 \mathrm{C} / \triangle \arg A^{2}\right)$ and KT207 $\left(\arg A^{\left.\mathrm{ATG} \mathrm{Y} 19 \mathrm{C} / \arg A^{+}\right)}\right.$strains. The growth and putrescine production of both KT39 and KT207 were not different. Thus, the presence of wildtype ArgA expressed from the genome does not affect the growth or putrescine production (Fig. 4).

The strong promoter T5p increases putrescine production- According to the report of Buch and Boyle (1985), a significant proportion of SpeA associates with the cell envelope. A recent paper reported that some of SpeA is in the periplasm and the other is in the cytoplasm (Meydan et al. 2019). Overexpression of membrane-associated or excreted proteins can affect cell health. Therefore, in this study, the promoter strength required for overexpression was of concern. The lacI, lacI ${ }^{\mathrm{q}}$, lacI ${ }^{\mathrm{q}}$, and $\mathrm{T} 5$ promoters were compared. The strain carrying the lacI 
promoter produced the lowest concentration of extracellular putrescine, whereas the strain carrying the $\mathrm{T} 5$ promoter produced the highest. Due to its affinity for RNA polymerase, the lacI promoter is the poorest (MullerHill et al. 1968). Therefore, the expression level is low. A point mutation at the -35 region of the $\operatorname{lacl}^{\mathrm{q}}$ promoter led to tenfold higher expression and the lac ${ }^{\mathrm{q} 1}$ promoter resulted in 170-fold higher expression (Calos 1978; Glascock and Weickert 1998; Penumetcha et al. 2010). Moreover, there are two lac operators in this T5 promoter with a strong affinity to E. coli RNA polymerase (von Gabain and Bujard 1977, 1979; Shibui et al. 1988), but no study has directly compared their affinity for RNA polymerase. As depicted in Fig. 5B, the putrescine production of KT148 (T5p) was higher than that of KT39 (lac I $\left.{ }^{\mathrm{q} 1} \mathrm{p}\right)$.

Effects of puuPA disruption on putrescine production- Two catabolic pathways of putrescine have been reported. PatA and PuuA are the first enzymes of the aminotransferase pathway and putrescine utilization pathway (the Puu pathway), respectively. PatA transfers one of the amino groups of putrescine to $\alpha$-ketoglutarate (Shaibe et al. 1985; Schneider and Reitzer 2012). Another enzyme that catabolizes putrescine is PuuA, which $\gamma$-glutamylates the amino group of putrescine to generate $\gamma$-glutamylputrescine. The proteins involved in the Puu pathway are encoded in a gene cluster. The importer of this Puu pathway is PuuP, which is encoded in this gene cluster. After PuuP transports putrescine into the cell, the degradation step begins with PuuA (Kurihara et al. 2009b). There is no report to compare the reaction velocity or the expression level between the puuA and patA yet. So, it is difficult to specify which enzymes are mainly work. However, according to our previous study, the deletion of the $p u u A$ gene caused a severe effect on putrescine utilization and $\triangle p u u A$ strain could not grow using putrescine as a nitrogen source or a carbon source, while the deletion of the patA gene did not affect this issue (Kurihara et al. 2008). The result in this study is agreeable with the previous study that the presence of puuA showed the degradation of putrescine while patA is not. In addition, under the condition in which putrescine is present, PuuP is required as a putrescine transporter to use putrescine as an energy source (Kurihara et al. 2009b; Terui et al. 2014). As PuuP may also have its own promoter, we constructed KT148 $(\triangle p u u A)$ and KT152 $(\triangle p u u A P)$ to investigate the relationship between these puuAP genes. As shown in Fig. 6, puuAP may be an operon because $\triangle p u u A P$ had the same result as $\triangle p u и A$. The deletion of $p u и A$ increased the extracellular accumulation of putrescine. In summary, PatA does not affect putrescine production, but the deletion of PuuA increases the amount of putrescine.
Terrific broth is a better medium for putrescine production- LB medium is widely used as a standard medium for a broad group of bacteria (Sezonov et al. 2007; Suzuki et al., 2019). However, the growth of $E$. coli is not high in the LB medium, whereas it is markedly high in terrific broth (Losen et al. 2004; Lessard 2013). Terrific broth contains $5.04 \mathrm{~g} / \mathrm{L}$ of glycerol, while LB medium does not. $E$. coli can utilize glycerol as a carbon source for growth and putrescine production. Besides much higher concentration of yeast extracts, this is one of the reasons why the growth and putrescine production in terrific broth is better than those in LB medium (Fig. 7).

Mutation of YifE increases putrescine- During we attempted to find a putrescine exporter in $E$. coli K-12, we found that the extracellular putrescine concentration of strain JW0484 with $\Delta y b b A::$ FRT- $k a n^{\mathrm{R}}$-FRT was approximately double that of its parental strain, ME9062 (Additional file 1: Fig. S1). The $\Delta y b b A:: F R T-k a n^{\mathrm{R}}$-FRT was transduced to strain MG1655 to confirm the increase of putrescine production. However, the extracellular putrescine concentration of the MG1655 with $\triangle y b b A:: F R T$ $k a n^{R}-$ FRT was not different from that of MG1655. We predicted that the second mutation in strain JW0484 increased the extracellular putrescine concentration. Then, its genome sequence was performed to evaluate this prediction. The result of genome sequencing showed several mutations in strain JW0484, which were not reported in strain ME9062. Additional mutations were found in int $A, f b a A, d g o R$, yifE, and lexA in the genome of strain JW0484. Further experiments revealed that mutation of the yifE gene increases the extracellular putrescine concentration (Additional file 1: Fig. S2). As shown in Fig. 8a, the YifE mutant was also effective in our putrescine over-producing strain (KT160). RT-PCR revealed that the yifE ${ }^{\mathrm{Q} 100 \mathrm{TAG}}$ mutation increases the transcription of $h d f R$ and $g l t B$ genes.

Pistocchi et al. (1993) reported that the PotFGHI transporter uptakes putrescine and accumulates it in the cell. Therefore, it is conceivable that PotFGHI reduces extracellular putrescine. We compared the strains with and without the PotFGHI transporter, but there was no difference in the concentration of putrescine between potFGHI ${ }^{+}$and $\triangle$ potFGHI strains. Thus, the PotFGHI transporter does not affect the amount of extracellular putrescine. Terui et al. (2014) reported that PotFGHI functions as a major transporter when putrescine is absent in the medium. However, the PotFGHI transporter can be inhibited by putrescine through a feedback loop. In our experimental condition, putrescine was synthesized and exported to the medium; therefore, PotFGHI may have been inhibited by putrescine. We achieved $19.8 \mathrm{mM}$ of putrescine production from KT160 in terrific 
broth. When compare in terms of the product yield, Qian et al. (2009) reported a yield of putrescine at $30.3 \mathrm{~g} / \mathrm{M}$ glucose, while our putrescine production is the $31.8 \mathrm{~g} / \mathrm{M}$ glycerol. However, as putrescine is an ionic compound, its production altered the $\mathrm{pH}$ of the medium during cultivation. As we do not have a bioreactor device, we were unable to assess continuous feeding with $\mathrm{pH}$ adjustment.

\section{Supplementary Information}

The online version contains supplementary material available at https://doi. org/10.1186/s13568-021-01330-5.

Additional file 1: Table S1. Primers used for strain construction. Table S2. Primers used for plasmid construction. Table S3. Primers used for Realtime PCR. Fig. S1. Comparison of extracellular putrescine concentration per $\mathrm{OD}_{600}$ among strains of the Keio collection. M9 glucose medium $(60 \mathrm{~mL}$ in 100-mL Erlenmeyer flask with stirrer bar) was inoculated with the preculture at the initial $O D_{600}$ of 0.06 . The flasks were set in the $7-L$ rectangular anaerobic jar with 2 AnaeroPack-Anaero sachets (Mitsubishi Gas Chemical; Tokyo, Japan) to form an anaerobic environment and the jar was set on the stirrer in the microbiological incubator. The culture medium was stirred at $150 \mathrm{rpm}$ and kept at $37^{\circ} \mathrm{C}$. After $10 \mathrm{~h}$ of incubation, the $\mathrm{OD}_{600}$ of the culture was measured and $0.4 \mathrm{~mL}$ of the culture was centrifuged. Thirty $\mu \mathrm{L}$ of $100 \%(\mathrm{w} / \mathrm{v}) \mathrm{TCA}$ was mixed with $0.3 \mathrm{~mL}$ of the supernatant, filtrated through the membrane filter, and then subjected to HPLC analysis as described in the main text. Asterisks indicate the genes with significant differences in transcription levels. Fig. S2. Q100TAG mutation in the yifE gene promotes putrescine production. Extracellular concentration of putrescine of $\mathrm{Al} 32$ (pQE-80L/MG1655, open diamond) and Al33 (pQE-80L::yifE ${ }^{\mathrm{Q} 100 T A G} / \mathrm{MG} 1655$, closed square) cultured at $37^{\circ} \mathrm{C}$ in minimal M9 supplemented with $0.2 \%$ glucose. $100 \mu \mathrm{g} / \mathrm{mL}$ of ampicillin was added to maintain the plasmids. When the $\mathrm{OD}_{600}$ reached 0.5 , the $0.5 \mathrm{mM} \mathrm{IPTG}$ was added. Fig. S3. The presence of $h d f R$ had a slight, if any, effect on the increase in extracellular putrescine concentration by YifE ${ }^{\mathrm{Q} 100 \mathrm{TAG}}$. (A) Cell growth and (B) extracellular concentration of putrescine of Al32 (pQE-80L/ MG1655, open circle), Al33 (pQE-80L::yifE $100 T A G / M G 1655$, closed triangle), and KT218 (pQE-80L::yifE 100 TAG / MG1655 but $\triangle h d f R:: F R T-k a n^{R}-F R T$, closed square) cultured at $37^{\circ} \mathrm{C}$ in LB supplemented with $100 \mu \mathrm{g} / \mathrm{mL}$ of ampicillin. When the $\mathrm{OD}_{600}$ reached $0.4,0.02 \mathrm{mM}$ IPTG was added.

\section{Acknowledgements}

Not applicable.

\section{Authors' contributions}

KT conducted all fermentation experiments in the main text and contributed to the interpretation, analyzation and preparation of the draft. KI constructed a plasmid and performed the primary fermentation experiments. YS and $\mathrm{Al}$ identified the yifE mutant and found that the mutation can increase putrescine production. HS planned the study, acquired the funding, led the project, constructed some strains and plasmids, and edited the manuscript.

\section{Funding}

This study was partially supported by funding from the Kinugasa Research Foundation for Textile Science.

\section{Availability of data and materials}

Some data are not shown in the text and supplement. However, they are available from the authors upon reasonable request. The strains and plasmids used in this work can be shared by exchanging MTA.

\section{Declarations}

Ethics approval and consent to participate

This article does not contain any studies with human participants or animals performed by any of the authors.
Consent for publication

Not applicable.

\section{Competing of interests}

The authors declare that there is no conflict of interest.

Received: 30 November 2021 Accepted: 4 December 2021

Published online: 15 December 2021

\section{References}

Baba T, Ara T, Hasegawa M, Takai Y, Okumura Y, Baba M, Datsenko KA, Tomita M, Wanner BL, Mori H (2006) Construction of Escherichia coli K-12 inframe, single-gene knockout mutants: the Keio collection. Mol Syst Biol 2:2006-2008. https://doi.org/10.1038/msb4100050

Buch JK, Boyle SM (1985) Biosynthetic arginine decarboxylase in Escherichia coli is synthesized as a precursor and located in the cell envelope. J Bacteriol 163:522-527. https://doi.org/10.1128/jb.163.2.522-527.1985

Calos MP (1978) DNA sequence for a low-level promoter of the lac repressor gene and an 'up' promoter mutation. Nature 274:762-765. https://doi. org/10.1038/274762a0

Datsenko KA, Wanner BL (2000) One-step inactivation of chromosomal genes in Escherichia coli K-12 using PCR products. Proc Natl Acad Sci U S A 97:6640-6645. https://doi.org/10.1073/pnas.120163297

Demco DE, Litvinov VM, Rata G, Popescu C, Phan KH, Schmidt A, Blümich B (2007) Investigation of thermal aging of polyamide 4,6 by $1 \mathrm{H}$ solid-state NMR. Macromol Chem Phys 208:2085-2095. https://doi.org/10.1002/ macp.200700095

Ginesy M, Belotserkovsky J, Enman J, Isaksson L, Rova U (2015) Metabolic engineering of Escherichia coli for enhanced arginine biosynthesis. Microb Cell Factories 14:29. https://doi.org/10.1186/s12934-015-0211-y

Glascock CB, Weickert MJ (1998) Using chromosomal lacle1 to control expression of genes on high-copy-number plasmids in Escherichia coli. Gene 223:221-231. https://doi.org/10.1016/s0378-1119(98)00240-6

Haywood GW, Large PJ (1985) The occurrence, subcellular localization and partial purification of diamine acetyltransferase in the yeast Candida boidinii grown on spermidine or putrescine as sole nitrogen source. Eur J Biochem 148:277-283. https://doi.org/10.1111/j.1432-1033.1985.tb088 $36 . x$

Heby O (1981) Role of polyamines in the control of cell proliferation and differentiation. Differentiation 19:1-20. https://doi.org/10.1111/j.1432-0436. 1981.tb01123.x

Hui H, Bai Y, Fan TP, Zheng X, Cai Y (2020) Biosynthesis of putrescine from L-arginine using engineered Escherichia coli whole cells. Catalysts 10:947. https://doi.org/10.3390/catal10090947

Igarashi K, Terui Y, Kashiwagi K (2015) The polyamine modulon: genes encoding proteins whose synthesis is enhanced by polyamines at the level of translation. In: Kusano T, Suzuki H (eds) Polyamines: a universal molecular nexus for growth, survival, and specialized metabolism. Springer, Tokyo, pp 131-1411. https://doi.org/10.1007/978-4-431-55212-3_11

Igarashi K, Kashiwagi K (2000) Polyamines: mysterious modulators of cellular functions. Biochem Biophys Res Commun 271:559-564. https://doi.org/ $10.1006 /$ bbrc.2000.2601

Igarashi K, Kashiwagi K (2010) Modulation of cellular function by polyamines. Int J Biochem Cell Biol 42:39-51. https://doi.org/10.1016/j.biocel.2009. 07.009

Igarashi K, Kashiwagi K (2018) Effects of polyamines on protein synthesis and growth of Escherichia coli. J Biol Chem 293:18702-18709. https://doi.org/ 10.1074/jbc.TM118.003465

Igarashi K, Kashiwagi K (2019) The functional role of polyamines in eukaryotic cells. Int J Biochem Cell Biol 107:104-115. https://doi.org/10.1016/j.biocel. 2018.12.012

Kashiwagi K, Miyamoto S, Suzuki F, Kobayashi H, Igarashi K (1992) Excretion of putrescine by the putrescine-ornithine antiporter encoded by the potE gene of Escherichia coli. Proc Natl Acad Sci USA 89:4529-4533. https://doi. org/10.1073/pnas.89.10.4529

Keller C, Chattopadhyay M, Tabor H (2019) Absolute requirement for polyamines for growth of Escherichia coli mutants ( $m n m E / G$ ) defective in modification of the wobble anticodon of transfer-RNA. FEMS Microbiol Lett 366:fnz110. https://doi.org/10.1093/femsle/fnz110 
Kurihara S, Oda S, Kato K, Kim HG, Koyanagi T, Kumagai H, Suzuki H (2005) A novel putrescine utilization pathway involves $\gamma$-glutamylated intermediates of Escherichia coli K-12.J Biol Chem 280:4602-4608. https://doi.org/ 10.1074/jbc.M411114200

Kurihara S, Oda S, Tsuboi Y, Kim HG, Oshida M, Kumagai H, Suzuki H (2008) $\gamma$-Glutamylputrescine synthetase in the putrescine utilization pathway of Escherichia coli K-12. J Biol Chem 283:19981-19990. https://doi.org/10. 1074/jbc.M800133200

Kurihara S, Suzuki H, Tsuboi Y, Benno Y (2009a) Dependence of swarming in Escherichia coli K-12 on spermidine and the spermidine importer. FEMS Microbiol Lett 294:97-101. https://doi.org/10.1111/j.1574-6968.2009. $01552 x$

Kurihara S, Tsuboi Y, Oda S, Kim HG, Kumagai H, Suzuki H (2009b) The putrescine importer PuuP of Escherichia coli K-12. J Bacteriol 191:2776-2782. https://doi.org/10.1128/JB.01314-08

Kurihara S, Suzuki H, Oshida M, Benno Y (2011) A novel putrescine importer required for type 1 pili-driven surface motility induced by extracellular putrescine in Escherichia coli K-12. J Biol Chem 286:10185-10192. https:// doi.org/10.1074/jbc.M1 10.176032

Lessard JC (2013) Growth media for E. coli. Methods Enzymol 533:181-189. https://doi.org/10.1016/B978-0-12-420067-8.00011-8

Li L, Zou D, Ji A, He Y, Liu Y, Deng Y, Chen S, Wei X (2020a) Multilevel metabolic engineering of Bacillus amyloliquefaciens for production of the platform chemical putrescine from sustainable biomass hydrolysates. ACS Sustain Chem Eng 8:2147-2157. https://doi.org/10.1021/acssuschemeng.9b054 84

Li G, Huang D, Wang L, Deng Y (2020b) Highly efficient whole-cell biosynthesis of putrescine by recombinant Escherichia coli. Biochem Eng J 166:107859. https://doi.org/10.1016/j.bej.2020.107859

Limsuwun K, Jones PG (2000) Spermidine acetyltransferase is required to prevent spermidine toxicity at low temperatures in Escherichia coli. J Bacteriol 182:5373-5380. https://doi.org/10.1128/JB.182.19.5373-5380.2000

Losen M, Frölich B, Pohl M, Büchs J (2004) Effect of oxygen limitation and medium composition on Escherichia coli fermentation in shake-flask cultures. Biotechnol Prog 20:1062-1068. https://doi.org/10.1021/bp034282t

Lu CD (2006) Pathways and regulation of bacterial arginine metabolism and perspectives for obtaining arginine overproducing strains. Appl Microbiol Biotechnol 70:261-272. https://doi.org/10.1007/s00253-005-0308-z

Meydan S, Marks J, Klepacki D, Sharma V, Baranov PV, Firth AE, Margus T, Kefi A, Vázquez-Laslop N, Mankin AS (2019) Retapamulin-assisted ribosome profiling reveals the alternative bacterial proteome. Mol Cell 74:481-493. https://doi.org/10.1016/j.molcel.2019.02.017

Michael AJ (2016) Polyamines in eukaryotes, bacteria, and archaea. J Biol Chem 291:14896-14903. https://doi.org/10.1074/jbc.R116.734780

Michael AJ (2018) Polyamine function in archaea and bacteria. J Biol Chem 293:18693-18701. https://doi.org/10.1074/jbc.TM118.005670

Miller J (1972) Experiments in molecular genetics. Cold Spring Harbor Laboratory, Cold Spring Harbor, NY

Müller-Hill B, Crapo L, Gilbert W (1968) Mutants that make more lac repressor. Proc Natl Acad Sci U S A 59:1259-1264. https://doi.org/10.1073/pnas.59.4. 1259

Nguyen LT, Lee EY (2019) Biological conversion of methane to putrescine using genome-scale model-guided metabolic engineering of a methanotrophic bacterium Methylomicrobium alcaliphilum 20Z. Biotechnol Biofuels 12:147. https://doi.org/10.1186/s13068-019-1490-z

Pegg AE (1986) Recent advances in the biochemistry of polyamines in eukaryotes. Biochem J 234:249-262. https://doi.org/10.1042/bj2340249

Penumetcha P, Lau K, Zhu X, Davis K, Eckdahl TT, Campbell AM (2010) Improving the Lac system for synthetic biology. Bios 81:7-15. https://doi.org/10. 1893/011.081.0104

Pistocchi R, Kashiwagi K, Miyamoto S, Nukui E, Sadakata Y, Kobayashi H, Igarashi K (1993) Characteristics of the operon for a putrescine transport system that maps at 19 minutes on the Escherichia coli chromosome. J Biol Chem 268:146-152

Qian ZG, Xia XX, Lee SY (2009) Metabolic engineering of Escherichia coli for the production of putrescine: a four carbon diamine. Biotechnol Bioeng 104:651-662. https://doi.org/10.1002/bit.22502

Rajagopal BS, DePonte J, Tuchman M, Malamy MH (1998) Use of inducible feedback-resistant $\mathrm{N}$-acetylglutamate synthetase $(\arg A)$ genes for enhanced arginine biosynthesis by genetically engineered Escherichia coli K-12 strains. Appl Environ Microbiol 64:1805-1811. https://doi.org/10. 1128/AEM.64.5.1805-1811.1998

Saier MH Jr, Reddy VS, Tsu BV, Ahmed MS, Li C, Moreno-Hagelsieb G (2016) The transporter classification database (TCDB): recent advances. Nucleic Acids Res 44:D372-D379. https://doi.org/10.1093/nar/gkv1103

Samsonova NN, Smirnov SV, Altman IB, Ptitsyn LR (2003) Molecular cloning and characterization of Escherichia coli K12 ygjG gene. BMC Microbiol 3:2. https://doi.org/10.1186/1471-2180-3-2

Samsonova NN, Smirnov SV, Novikova AE, Ptitsyn LR (2005) Identification of Escherichia coli $\mathrm{K} 12 \mathrm{YdcW}$ protein as a $\mathrm{Y}$-aminobutyraldehyde dehydrogenase. FEBS Lett 579:4107-4112. https://doi.org/10.1016/j.febslet.2005. 06.038

Sanders J, Scott E, Weusthuis R, Mooibroek H (2007) Bio-refinery as the bioinspired process to bulk chemicals. Macromol Biosci 7:105-117. https:// doi.org/10.1002/mabi.200600223

Schneider BL, Reitzer L (2012) Pathway and enzyme redundancy in putrescine catabolism in Escherichia coli. J Bacteriol 194:4080-4088. https://doi.org/ 10.1128/JB.05063-11

Schneider J, Wendisch VF (2010) Putrescine production by engineered Corynebacterium glutamicum. Appl Microbiol Biotechnol 88:859-868. https://doi.org/10.1007/s00253-010-2778-x

Schneider J, Wendisch VF (2011) Biotechnological production of polyamines by bacteria: recent achievements and future perspectives. Appl Microbiol Biotechnol 91:17-30. https://doi.org/10.1007/s00253-011-3252-0

Scott E, Peter F, Sanders J (2007) Biomass in the manufacture of industrial products-the use of proteins and amino acids. Appl Microbiol Biotechnol 75:751-762. https://doi.org/10.1007/s00253-007-0932-x

Sezonov G, Joseleau-Petit D, D'Ari R (2007) Escherichia coli physiology in Luria-Bertani broth. J Bacteriol 189:8746-8749. https://doi.org/10.1128/ JB.01368-07

Shaibe E, Metzer E, Halpern YS (1985) Metabolic pathway for the utilization of L-arginine, L-ornithine, agmatine, and putrescine as nitrogen sources in Escherichia coli K-12. J Bacteriol 163:933-937. https://doi.org/10.1128/jb. 163.3.933-937.1985

Shibui T, Uchida M, Teranishi Y (1988) A new hybrid promoter and its expression vector in Escherichia coli. Agr Biol Chem 52:983-988. https://doi.org/ 10.1080/00021369.1988.10868770

Shin JH, Lee SY (2014) Metabolic engineering of microorganisms for the production of L-arginine and its derivatives. Microb Cell Factories 13:166. https://doi.org/10.1186/s12934-014-0166-4

Sugiyama Y, Nakamura A, Matsumoto M, Kanbe A, Sakanaka M, Higashi K, Igarashi K, Katayama T, Suzuki H, Kurihara S (2016) A novel putrescine exporter SapBCDF of Escherichia coli. J Biol Chem 291:26343-26351. https://doi.org/10.1074/jbc.M116.762450

Sun X, Song W, Liu L (2015) Enzymatic production of agmatine by recombinant arginine decarboxylase. J Mol Catal B Enzym 121:1-8. https://doi. org/10.1016/j.molcatb.2015.06.008

Suzuki H, Nishida K, Tamaki H (2019) Shochu slop is an excellent medium for Escherichia coli K-12. Lett Appl Microbiol 68:505-508. https://doi.org/10. 1111/lam.13148

Tabor CW, Tabor H (1985) Polyamines in microorganisms. Microbiol Rev 49:81-99

Tabor CW, Tabor H, Xie QW (1986) Spermidine synthase of Escherichia coli: localization of the speE gene. Proc Natl Acad Sci U S A 83:6040-6044. https://doi.org/10.1073/pnas.83.16.6040

Terui Y, Saroj SD, Sakamoto A, Yoshida T, Higashi K, Kurihara S, Suzuki H, Toida T, Kashiwagi K, Igarashi K (2014) Properties of putrescine uptake by PotFGHI and PuuP and their physiological significance in Escherichia coli. Amino Acids 46:661-670. https://doi.org/10.1007/s00726-013-1517-x

Thongbhubate K, Nakafuji Y, Matsuoka R, Kakegawa S, Suzuki H (2021) Effect of spermidine on biofilm formation in Escherichia coli K-12. J Bacteriol 203:e00652-e720. https://doi.org/10.1128/JB.00652-20

von Gabain A, Bujard H (1977) Interaction of E. coli RNA polymerase with promotors of coliphage T5. Mol Gen Genet 157:301-311. https://doi.org/ 10.1007/BF00268667

von Gabain A, Bujard H (1979) Interaction of Escherichia coli RNA polymerase with promoters of several coliphage and plasmid DNAs. Proc Natl Acad Sci U S A 76:189-193. https://doi.org/10.1073/pnas.76.1.189

Wendisch VF, Mindt M, Pérez-García F (2018) Biotechnological production of mono-and diamines using bacteria: recent progress, applications, and 
perspectives. Appl Microbiol Biotechnol 102:3583-3594. https://doi.org/ 10.1007/s00253-018-8890-z

Xu D, Zhang L (2019a) Metabolic engineering of Escherichia coli for agmatine production. Eng Life Sci 19:13-20. https://doi.org/10.1002/elsc.20180 0104

Xu D, Zhang L (2019b) Increasing agmatine production in Escherichia coli through metabolic engineering. J Agric Food Chem 67:7908-7915. https://doi.org/10.1021/acs.jafc.9b03038

Yamanobe T, Kurihara Y, Uehara H, Komoto T (2007) Structure and characterization of nylon 46. J Mol Struct 829:80-87. https://doi.org/10.1016/j.molst ruc.2006.06.010

Yoshida M, Kashiwagi K, Shigemasa A, Taniguchi S, Yamamoto K, Makinoshima $\mathrm{H}$, Ishihama A, Igarashi K (2004) A unifying model for the role of polyamines in bacterial cell growth, the polyamine modulon. J Biol Chem 279:46008-46013. https://doi.org/10.1074/jbc.M404393200

\section{Publisher's Note}

Springer Nature remains neutral with regard to jurisdictional claims in published maps and institutional affiliations.

\section{Submit your manuscript to a SpringerOpen ${ }^{\odot}$ journal and benefit from:}

- Convenient online submission

- Rigorous peer review

- Open access: articles freely available online

- High visibility within the field

- Retaining the copyright to your article

Submit your next manuscript at $\boldsymbol{\nabla}$ springeropen.com 